Bryn Mawr College

Scholarship, Research, and Creative Work at Bryn Mawr College

Graduate School of Social Work and Social

Graduate School of Social Work and Social

Research Faculty Research and Scholarship

Research

2003

\title{
The Bottom Line: Employment and Barriers to Work among Former SSI DA\&A Beneficiaries
}

Kevin Campbell

Jim Baumohl

Bryn Mawr College, jbaumohl@brynmawr.edu

Sharon R. Hunt

Let us know how access to this document benefits you.

Follow this and additional works at: http://repository.brynmawr.edu/gsswsr_pubs

Part of the Social Work Commons

\section{Custom Citation}

Campbell, Kevin, Jim Baumohl, and Sharon R. Hunt. "The Bottom Line: Employment and Barriers to Work among Former SSI DA\&A Beneficiaries." Contemporary Drug Problems 30, no. 1/2 (2003): 195-240.

This paper is posted at Scholarship, Research, and Creative Work at Bryn Mawr College. http://repository.brynmawr.edu/gsswsr_pubs/45

For more information, please contact repository@brynmawr.edu. 


\section{The bottom line: employment and barriers to work among former SSI DA\&A beneficiaries}

BY KEVIN CAMPBELL, JIM BAUMOHL, AND SHARON R. HUNT

The Supplemental Security Income (SSI) program for drug addicts and alcoholics (DA\&A beneficiaries) ended in January 1997 without any special effort to create employment for those who lost benefits. Relying on data from a nine-site, two-year panel study of 1,764 former DA\&A recipients and detailed semistructured interviews with subsamples in four sites, this paper examines employment outcomes and barriers to employment among 611 respondents who lost SSI and did not replace it with another form of publicly funded income assistance. Despite the tight labor market of the late 1990s, this group was plagued by widespread unemployment and sub-employment. At the two-year follow-up, only $25 \%$ earned $\$ 500$ per month or more, and only $12 \%$ typically earned this much throughout the study. Given their age, health problems and limited human capital, it is likely that many former $D A \& A$ beneficiaries will remain indigent, returning to the SSI rolls when they requalify upon turning 65.

KEY WORDS: Supplemental Security Income (SSI), welfare, employment, mixed methods, disability, substance abuse.

(C) 2003 by Federal Legal Publications, Inc. 
January 1997 marked the end of the Supplemental Security Income (SSI) program for about 167,000 people with disabilities "materially related" to drug addiction and alcoholism. ${ }^{1}$ These "DA\&A" beneficiaries (as they were called) did not receive benefits after 1996 unless they had applied to the Social Security Administration for redetermination and been found eligible by virtue of other impairments or a finding that their DA\&A classification resulted from administrative error. By the end of 1997, only 35\% had requalified (Lewin and Westat, 1998). This was less than half the anticipated requalification rate of $75 \%$ (Congressional Budget Office, 1995).

The DA\&A program was terminated with little sense of what would happen to those who lost its support. Congress authorized no special effort to promote their employment. Still, Representative E. Clay Shaw, Jr. (R-FL), an architect of the program's demise, told National Public Radio (1999): "I figured some of them would certainly be going to work and have to realize that they'd have to get up in the morning and support themselves." In this paper, we take up how (and if) former DA\&A recipients who lost SSI replaced it with employment of some sort in the two years following the program's end. We consider the stability and yield of work, as well as obstacles to getting it and keeping it. In the Results section of the paper, we rely mainly on quantitative findings from our nine-site, two-year panel study. In the Discussion section, we interpret these results with the aid of qualitative data from subsamples interviewed in depth at four sites between the 12- and 18-month follow-ups. The concluding paper in this issue attends to the policy implications of our findings.

\section{Employment and barriers to employment among welfare recipients}

With unemployment rates falling steadily during the course of our study (reaching $4.3 \%$ in December 1998), employment 
prospects for welfare recipients were never better. During 1997 and 1998, the robust American economy contributed mightily to a $30 \%$ decline in the average number of families on the rolls of Aid to Families with Dependent Children (AFDC) and its successor, Temporary Assistance for Needy Families (TANF) (U.S. Department of Health and Human Services, 1999). ${ }^{2}$

Unfortunately there is neither a published nor a fugitive literature on the employment experiences of the population of interest to us. ${ }^{3}$ Moreover, useful studies of state and local General Assistance (GA) recipients, the welfare population most similar to SSI DA\&A beneficiaries, ${ }^{4}$ are extremely rare. Henly and Danziger (1996) found that only $31.4 \%$ of their sample of Michigan GA recipients found employment (not further defined) in the year following termination of that program in October 1991. These disqualified GA recipients left the rolls in the midst of dull economic times, however, not during the boom that began later in the decade.

Far richer and more temporally relevant data are available on the adult TANF population. A meta-analysis of studies examining employment outcomes among former AFDC and TANF parents whose benefits ended between July 1995 and August 1998 reported point-in-time employment rates ranging from $55 \%$ to $71 \%$ (Brauner and Loprest, 1999). The same study found that, nationwide, wages for those leaving the rolls typically were less than seven dollars per hour. Most of those employed failed to earn enough to rise above the poverty level; $33 \%-50 \%$ reported a decline in total household income. This was likely due to rapid job loss. A study of AFDC parents found that $45 \%$ of those who found work lost their jobs within four months; $75 \%$ lost them within one year (Rangarajan et al., 1998). ${ }^{5}$

Such discouraging results in view of the tightening labor market, and the emphasis in most TANF programs on moving recipients rapidly into jobs, suggested to many observers that 
a sizable welfare residuum is comprised of people facing significant "barriers to employment" (Danziger et al., 1999). In a review of the empirical literature on the impairments of TANF parents, Sweeney (2000) provided a catalogue of health conditions identified as employment barriers by studies in 24 states. A number of these inquiries-in Michigan, Minnesota, Indiana, Kansas, New Jersey, and Utah-demonstrated that various constellations of obstacles are associated with a failure to work. In one of the best-designed studies, Danziger et al. (1999) identified 14 potential employment barriers among single mothers sampled from the TANF rolls in an urban Michigan county in February 1997. Examining the prevalence of these barriers (alone or in combination) and their relationship to subsequent employment, they found problematic transportation to be most common (47\%), followed by inadequate education $(30 \%)$ and the presence of a major depressive disorder $(27 \%)$. Sparse work experience, few job skills, family health problems, and perceived workplace discrimination (on the basis of race, gender, or welfare status) also were significantly and negatively related to employment. Fully $85 \%$ of these TANF mothers reported at least one barrier, $37 \%$ reported two or three, and $27 \%$ reported four or more. The probability that a respondent worked 20 or more hours a week decreased substantially as the number of obstacles rose: Compared with those with none, women with one barrier were 1.9 times less likely to work 20 or more hours per week, and women reporting four to six barriers were 6.7 times less likely to work that much.

However, former SSI DA\&A recipients are quite dissimilar to the TANF group, which is about $90 \%$ female and, per eligibility rules, caring for children. TANF parents are also young (largely ages 18-35), and, stereotypes notwithstanding, relatively few seem to be substance abusers. While some studies using less stringent criteria have produced plausible rates as high as $20 \%$ (see Sweeney, 2000), using the DSM-III-R, Danziger et al. (1999) found that only $6 \%$ of their Michigan 
sample met the standards for drug or alcohol dependence during the previous 12 months. By contrast, most DA\&A beneficiaries were 35-50 years old and likely would have met dependence criteria in the relatively recent past.

That our respondents qualified at some point for SSI indicates how different they are from members of other welfare populations. By design, the Social Security Administration's standard of disability is quite strict. SSI eligibility hinges on independent medical evidence of impairment serious enough to prevent for at least a 12-month period the performance of "substantial gainful activity (SGA)," a Social Security term that over the course of this study referred to earnings of merely $\$ 500$ per month or more. ${ }^{6}$ As a San Francisco respondent observed about his ultimately successful redetermination: "I had interviews with physical doctors, two of them, and two mental assessments. . . . [T] hey want $100 \%$ of either mental or physical, but like I got $80 \%$ mental and $80 \%$ physical. . . . So to me that adds up to $160 \%$ of being $100 \%$ fucked up." It is unlikely that the self-reported impairments of TANF parents are comparable to those underlying the certified work disability of SSI beneficiaries. ${ }^{3}$

Former DA\&A recipients and TANF parents probably have meager skills and work histories in common, however. A California study of an ill-defined population of "welfare recipients" found that $76 \%$ had either "low" or "very low" job skills, meaning they would have difficulty performing the simple arithmetic operations necessary in many clerical and service jobs (Johnson and Tafoya, 1999). In a somewhat more positive vein, Danziger et al. (1999) found that $80 \%$ of their TANF mothers (70\% of whom were high school graduates) were familiar with at least four of nine basic job skills. A study of Florida TANF mothers interviewed in 1998 reported that $12 \%$ had never held a full-time job and that of those who had, $35 \%$ had worked full-time for a year or less and $56 \%$ for two years or less. Almost two-thirds had no skill or occupation (Merrill et al., undated). We have no comparable data on 
former DA\&A recipients. However, to qualify for SSI, individuals must not only be very poor and disabled by a rigorous standard, they also must not have worked more than $25 \%$ of the time after age 21 nor more than five of the previous 10 years (Mashaw and Reno, 1996). Such work histories and the humble educational attainments of former DA\&A recipients (in our study, only $55 \%$ had completed high school or earned a General Equivalence Diploma) do not suggest the possession of readily marketable skills.

Even the roaring economy of the late 1990s seems not to have produced enough jobs for people with such modest ability. Based on a study of 125 cities, the National Conference of Mayors projected that between 1998 and 2003 there would be two unskilled job seekers for every unskilled-job (U.S. Conference of Mayors, 1997). This "job gap" was greatest in the biggest cities, particularly those with the largest concentrations of welfare recipients. The most striking shortfall is anticipated in Detroit, where 24 applicants are expected for each unskilled-job opening. At the other extreme, an unskilled-job surplus is expected in San Francisco, estimated to have four unskilled jobs for every taker in the next few years. Although not selected on this criterion, among the SSI Study sites are cities at each end of the job-gap spectrum. Table 1 displays these data for all sites in our study except Stockton, for which they were not available.

Given these conditions and the differences between the SSI and the TANF populations noted above, we would expect DA\&A beneficiaries expelled from SSI to do at least as poorly in the job market as adult TANF recipients. That is, we would expect their post-assistance employment to be unskilled, sporadic, and unremunerative. 


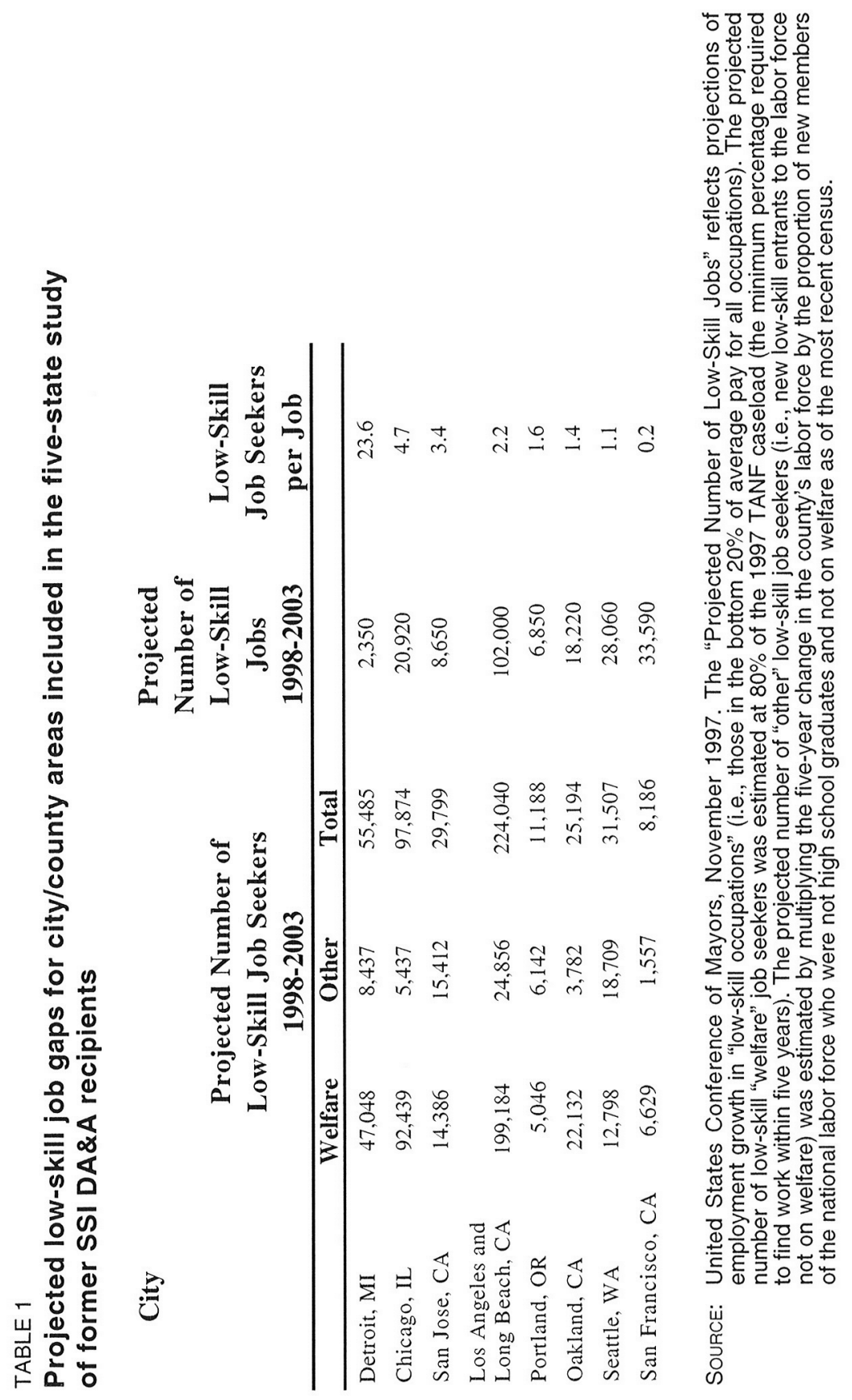




\section{Methods}

Study The methods of our nine-site, two-year panel study are sample described in detail in Swartz, Tonkin and Baumohl (this issue). We will not rehearse them here. Of the 1,764 former SSI DA\&A recipients interviewed at baseline, $152(9 \%)$ are not included in the analyses reported in this paper: $71(4 \%)$ died during the study, $68(4 \%)$ were lost to both the 18-and 24-month follow-ups, and 13 cases $(1 \%)$ lacked data critical to our analyses. Thus a total of 1,612 respondents are included here. Of these, we analyzed employment outcomes only among those who lost SSI and did not replace it with another form of publicly funded income assistance $(n=611)$. Put another way, we did not include respondents in analyses of employment outcomes if they requalified for SSI $(n=674)$ or regularly received benefits from programs like TANF or $\mathrm{GA}$, or collected a veteran's pension $(\mathrm{n}=327)$. In the assisted groups, employment rates were low at baseline (generally less than $10 \%$ ) and remained low throughout the study. ${ }^{10}$ Finally, we did not include respondents in analyses of employment rates for any round in which they reported jail or prison as their primary residence. Because of this wave-specific exclusion, the " $n$ " varies slightly across rounds. We excluded $4 \%$ of former DA\&A beneficiaries without income assistance from the calculation of baseline rates for this reason; we removed $7.2 \%-8.5 \%$ from employment-rate calculations for the six-through 24-month follow-ups.

\section{Indicator development}

Construction of outcome indicators
Participation in Publicly Funded Income Assistance Programs: We estimated rates of participation in these programs by classifying individuals according to the regularity with which they received benefits. Table 2 details our protocol for identifying Requalified SSI Beneficiaries, Non-SSI Income Assistance Recipients, and Former SSI Beneficiaries without Income Assistance. 


\begin{abstract}
\begin{tabular}{l|l} 
TABLE 2 & Protocol for classifying respondents by type of
\end{tabular} publicly funded income assistance received in the 24 months following termination of the SSI DA\&A program

Classification

Operational Definition

Requalified SSI Beneficiaries

Respondent usually" received SSI benefits during the 24-month follow-up period.

Non-SSI Income Assistance Recipients

Respondent did not usually receive SSI benefits during the 24-month follow-up but usually received some form of publicly funded income assistance that could be used customarily to pay for housing (e.g., General Assistance or TANF, but not food stamps). Respondent did not usually receive SSI benefits or

Former SSI Beneficiaries w/o Income non-SSI income assistance during the 24 -month followAssistance up.

a "Usually" means that a respondent reported receiving such benefits at the majority of follow-up interviews completed (i.e., two interviews if only two follow-up interviews were completed; at least two interviews if three follow-ups were completed; and at least three interviews if four follow-ups were completed).
\end{abstract}

Employment Rates: We estimated employment rates based on responses to structured interview questions about income from employment in the 30 days prior to the interview. Respondents were considered employed at a given follow-up if they reported any earnings (one dollar or more) from a "legitimate job or business" or "casual work or under-thetable jobs." Similarly, we considered respondents to be "usually" employed during the follow-up period if they reported employment earnings for the majority of interviews completed. To be sure, this is a very generous definition of employment. However, it has a compelling virtue in this case: As no definition could be more liberal, we eliminate the possibility that poor employment outcomes are the result of definitional gerrymandering. In this sense, a very liberal definition provides a very conservative test.

Work Retention Rates: By the same logic, we use a very liberal definition of continuous employment. We identified respondents who reported no income from employment in the month prior to the baseline interview but reported employment income at some time during the 24-month follow-up. For present purposes, we take these respondents as those who 
newly entered the workforce following elimination of the DA\&A program, and they form the denominator for calculation of six-month work-retention rates. Treating the follow-up at which these respondents first reported employment income as the "index," we considered them to have retained employment for six months if they reported employment income in the follow-up immediately after this index date. These respondents form the numerator for the calculation. If data were missing on questions about employment in the followup immediately after the index date, or if a respondent was not interviewed at the necessary follow-up, we did not calculate a work-retention rate. Overall, we calculated six-month retention rates for $84 \%$ of these "new" workers.

Employment Earnings: We calculated employment earnings for each respondent by summing the amount of income reported from a "legitimate job or business" and "casual work or under-the-table jobs" in the 30 days prior to the interview.

Performance of Substantial Gainful Activity: The consistent performance of SGA is taken by the Social Security Administration to indicate the absence of a work-disabling impairment. The SGA level of $\$ 500$ per month during the study period also corresponded closely to the unsupplemented minimum value of an SSI grant, thus representing a useful surrogate for the amount of SSI income in most states." Setting aside the value of Medicaid benefits, to have earned the SGA level each month during this study was to effectively have replaced the cash value of SSI. For each round of interviews, we classified respondents as achieving SGA if they reported earning $\$ 500$ or more per month from a "legitimate job or business" and/or "casual work or under-the-table jobs." Respondents were classified as "usually" earning SGA if they reported such income at the majority of follow-ups completed. Note, however, that our definition does not fully capture the meaning of SGA, because the Social Security Administration also counts income from illegal sources when 
known. We have not included such income here for reasons we take up in the Discussion section, below.

Barriers to As detailed in Table 3, we created indicators to represent employment whether a respondent experienced each of eight barriers to employment. Table 3 also compares the operational definition for each of our barriers with those used by Danziger et al. (1999). Our definitions were similar for obstacles related to education and to domestic abuse, but others differed substantially. Arguably, the Danziger group's constructions of mental-health and substance-abuse barriers are superior to ours because they are based on reasonably precise (or at least accepted) diagnostic criteria. Similarly, to identify physicalhealth barriers they used a functioning scale with national, age-specific norms, while we did not. We departed deliberately from their construction of a transportation barrier because we did not believe that lack of a car or driver's license constituted per se an obstacle to employment in most of our sites. We did not measure equivalents of their barriers related to childcare, understanding workplace norms, or perceived discrimination at work. Unlike the Danziger group, we included a housing barrier based on indications of literal homelessness. Finally, Danziger and her colleagues included a "work experience" barrier, considering it to be present if a respondent had worked less than $20 \%$ of the years since she turned 18. By definition, SSI recipients have little or no recent work experience, and virtually all of our respondents would have met this or a similar criterion.

Given the small sample sizes $(\mathrm{n}<100)$ in the sites for which we conducted the barrier analysis, we had to use three categories in order to calculate odds ratios. We created a threecategory indicator to reflect the number of barriers that each respondent experienced: zero or one; two or three; or four or more. 


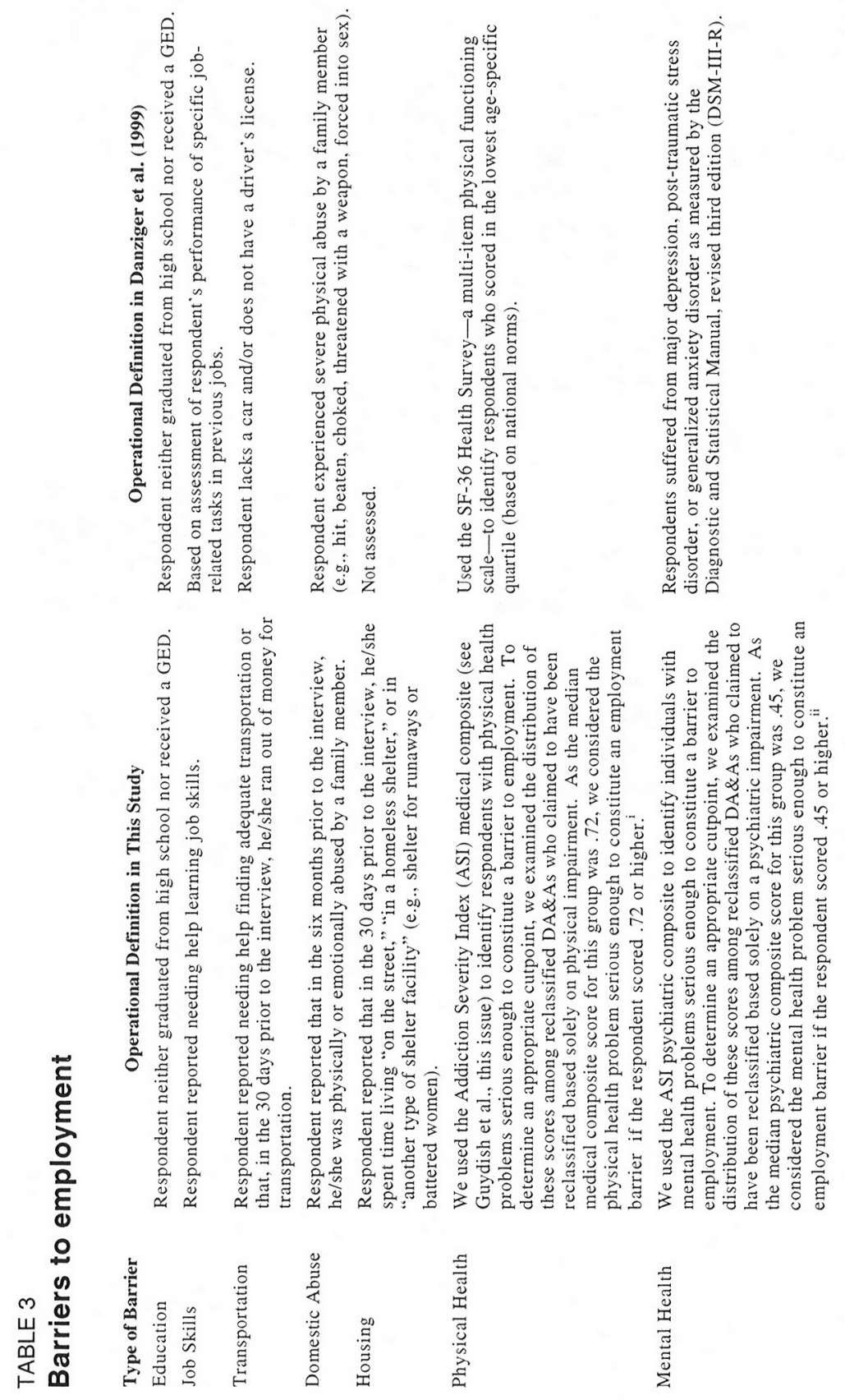



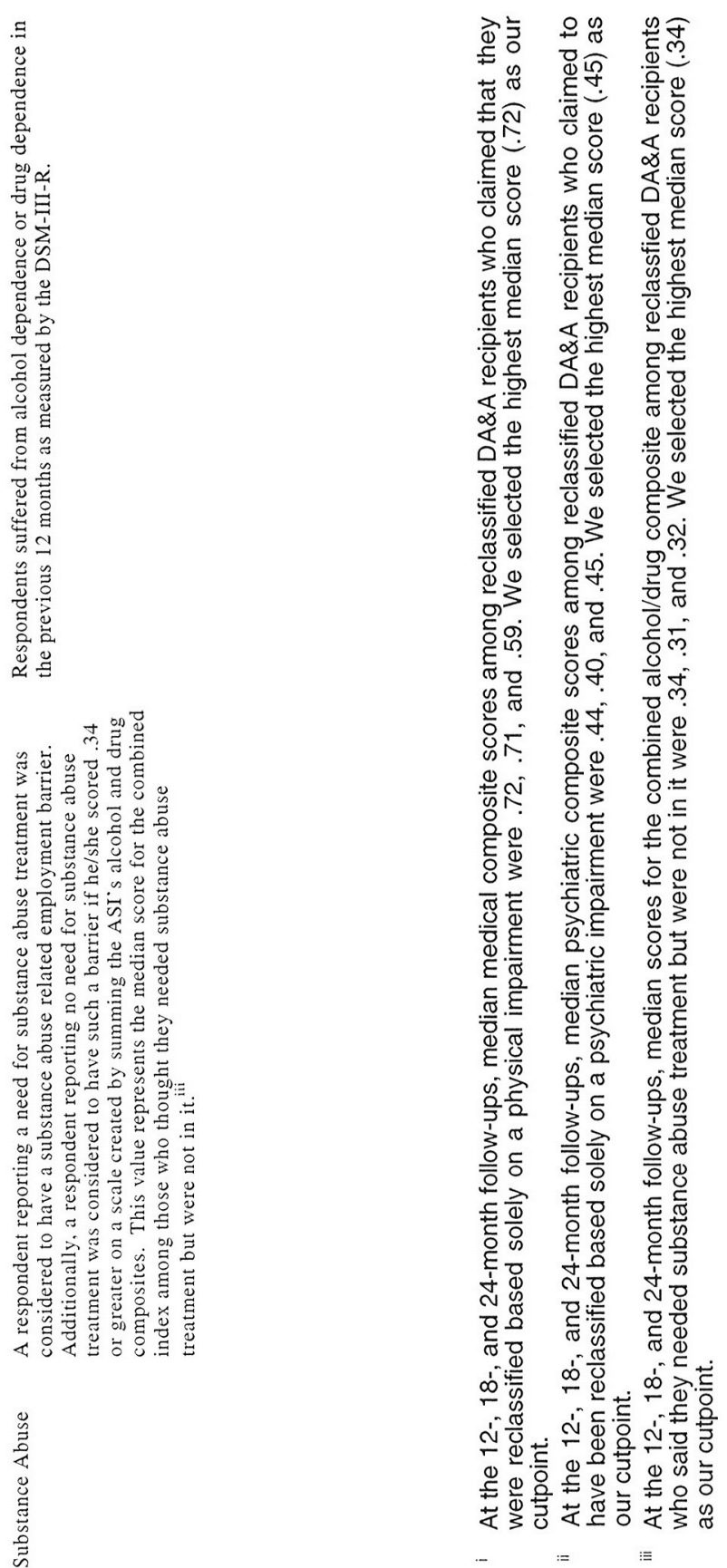
Analytic All analyses described below were conducted with data methods weighted according to the specifications detailed by Choudhry and Helba (this issue). All sample sizes are expressed in their unweighted forms.

Statistical We used WesvarPC and SAS's PROC GENMOD to conduct software statistical analyses. We did bivariate analyses and logistic regression with Wesvar, using PROC GENMOD for logit analysis of longitudinal data. PROC GENMOD is analogous to logistic regression but allows incorporation of individuals, responses at several points in time by adjusting for autocorrelation (Allison, 1999). Ideally, we would have used Wesvar throughout because, as Choudhry and Helba (this issue) explain, "the complex weighting required to adjust for incomplete frames and nonresponse" render inappropriate "variance estimation techniques typically used by statistical software packages (e.g., SPSS, SAS)." While WesVarPC provides accurate estimates of variance, it does not currently perform longitudinal analyses. Although it is not technically appropriate to use software packages such as SPSS or SAS on our weighted data, results from bivariate analyses and multiple logistic regression using them were-for all practical purposes-identical to WesVarPC's. We therefore have confidence in the results obtained from PROC GENMOD.

Summary of We report four sets of site-specific analyses. Recall that our analyses employment analyses include only respondents without income assistance.

First, we estimate SSI requalification rates for each site as well as utilization rates for non-SSI, publicly funded income assistance programs.

Second, we identify population trends in employment rates and earnings. Specifically, we compare employment rates at baseline with those at 24 months and identify sites where the gain was statistically significant. 
Third, we estimate rates of "usual" employment (the proportion of respondents employed at the majority of follow-ups). We also identify baseline predictors of usual employment during the follow-up period. To this end, we assessed a variety of baseline indicators as potential predictors: gender, age, education, ethnicity, each of the eight employment barriers, employment status at baseline, and abstinence from alcohol and drugs. We first examined the bivariate relationships between each of the predictors and our indicator of usual employment. We then included significant bivariate predictors in a multivariate logistic regression model to identify independent predictors of usual employment.

Across all sites, only 101 former DA\&A recipients without income assistance (17\% of that group) were employed at baseline, and 32 of them were in Chicago. In the remaining sites, the number employed at baseline ranged from four to 14. The limited power associated with these small numbers undermines our ability to identify site-specific differences in employment outcomes between those who were employed at baseline and those who were not. Still, we looked for such differences and report them where found. Where we did not find site-specific differences, we combine respondents across sites and compare aggregate outcomes between those employed or not employed at baseline.

Last, we explore the relationship between the types and number of work barriers and performance of SGA. This series of analyses uses PROC GENMOD to model employment at the SGA level as a function of time and of number and types of barriers. Since our concern is with the relationships between the number and types of barriers and SGA, we report only odds ratios associated with these relationships. A graphic representation of changes in employment at the SGA level as a function of time can be found in Figure 3. To verify the independence of observed relationships between number and types of barriers and employment at the SGA level, we introduced gender, race/ethnicity, age, receipt of income assis- 
Qualitative analysis of semistructured interview data tance, and employment status at baseline into the model. As a rule, adding these variables did not affect the statistical significance or magnitude of observed relationships, but on those occasions when it did, inclusion usually strengthened the relationship. (That is, it increased the magnitude of the odds ratio or lowered the $p$ value.) In these analyses, we used data from only six of the nine sites: Seattle, Portland, Chicago, Detroit, Stockton, and Los Angeles. We excluded San Francisco, Oakland, and San Jose because of their extremely small numbers (21-33) of former DA\&A recipients without income assistance. Finally, this longitudinal analysis excludes data from the baseline interview because, for the most part, respondents still received SSI at baseline.

To help interpret our findings, we use data from semistructured interviews conducted in Portland, San Francisco, Stockton, and Chicago between late March and late May of 1998; that is, between the one-year and 18-month structured interviews. As Swartz, Tonkin and Baumohl describe in more detail, we have data from 156 such interviews, but here we rely on the 73 conducted with respondents falling into the "no income assistance" group defined above.

Our lengthy conversations with these respondents yielded detailed work histories and information about current employment and other resource-generating activities. These data are far more detailed than those that could be collected by the structured interviews, and by design they cover periods of time before the study and between interviews that the scripted employment questions do not. The narrative data provide a vivid sense of what we count as work and income in our quantitative analyses, a matter of some importance, as we will see. In the concluding sections of this paper we rely extensively on the narrative data to explore the work our respondents did and their subjective understandings and definitions of it. 
We analyzed the voluminous semistructured interview data with the help of software called QSR NUD*IST, version 4 (N4). In its most basic application, N4 is an infinitely flexible electronic filing system that permits multiple-category coding of bits of text that can be viewed categorically and in original context. However, N4 also can execute complicated sequences of logical exercises (called "operators" in N4 lingo) that organize coded text to permit the identification of patterns and the testing of hypotheses with an efficiency that manual qualitative analysis cannot achieve. Further, text in $\mathrm{N} 4$ can be linked to quantitative data in spreadsheet format. For the analyses summarized in this paper, we used the unique identification numbers of respondents to connect their structured and semistructured interview data. For each analysis we used the identification numbers to disaggregate the semistructured interview sample by each category of interest (those employed at the level of SGA, for example, or those working at baseline).

\section{Results}

Type of The proportion of former DA\&A recipients who requalified income for SSI and thus received benefits throughout the study assistance ranged from $62 \%$ in San Francisco to $25 \%$ in Chicago (Figure received 1). The proportion usually receiving non-SSI income assistance ranged from $8 \%$ in Detroit to $29 \%$ in Los Angeles, and the proportion receiving no assistance of any kind varied from $17 \%$ in San Francisco to $62 \%$ in Chicago. These differences reflect local particularities of SSI qualification and requalification (especially the presence of active advocacy organizations) and variations in state and county GA and TANF programs. They are also related to the demographic characteristics of the samples in each site, particularly sex (closely associated with TANF utilization) and age (related to GA and SSI eligibility). Clearly there were large differences among sites in the extent to which public assistance of some 


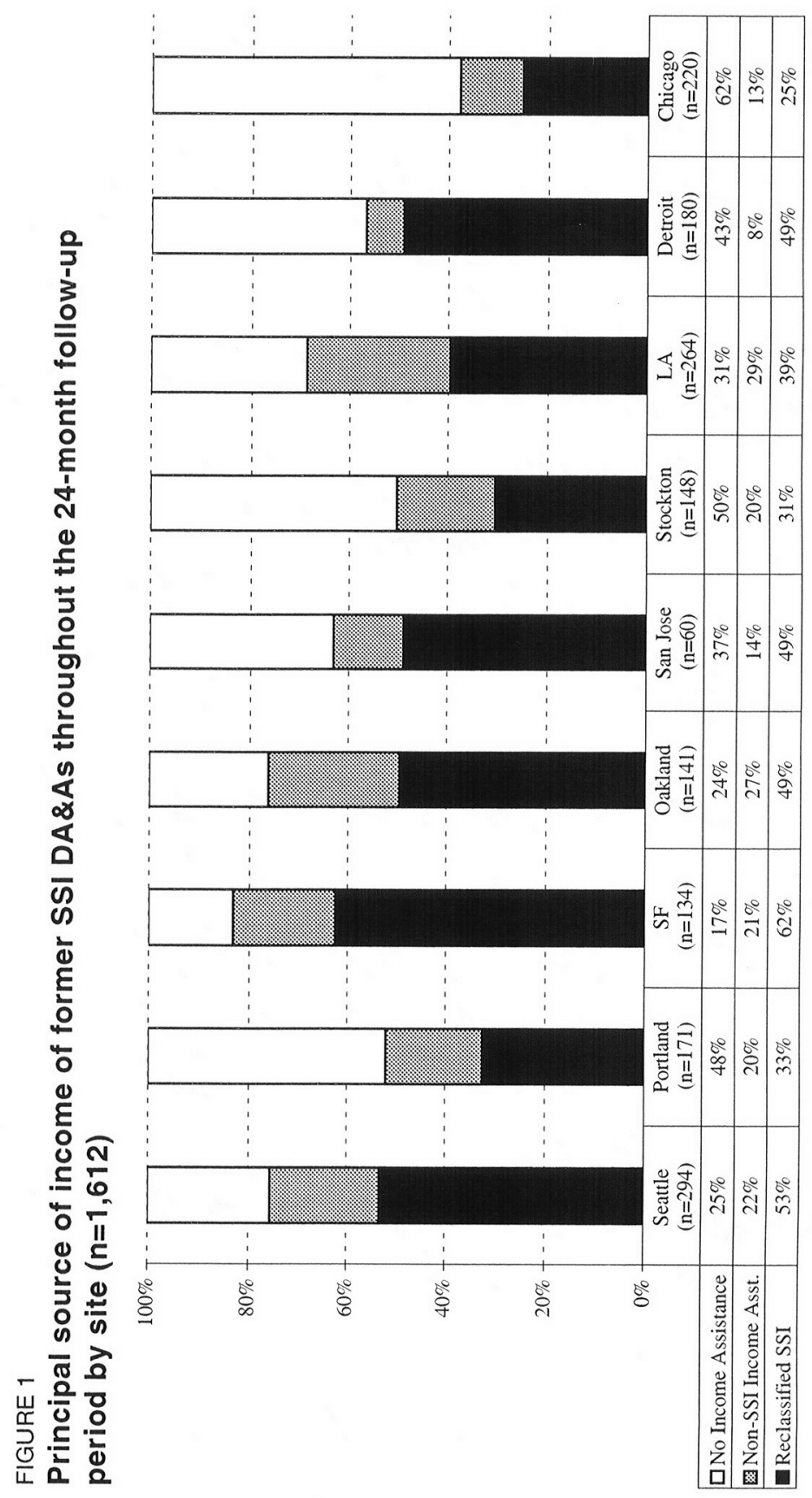


kind protected respondents from full exposure to the labor market. For this and other, similar reasons, we report our results by site whenever possible.

Population trends in employment outcomes

Employment rates

Earned income

Rates of Any Employment (monthly earnings of $\$ 1$ or more): Among those with whom our analysis is concerned, former DA\&A recipients without income assistance, employment rates increased significantly in all sites (Figure 2). In most places they rose from a $16 \%-20 \%$ level at baseline to $40 \%-60 \%$ at 24 months. As a rule, these increases were realized by six months. In the simplest sense, then, substantially greater numbers of respondents were working at the end of the study than at the beginning.

Rates of Employment at the SGA Level (monthly earnings of $\$ 500$ or more): When we look at a more meaningful measure of (albeit modest) work, the somewhat encouraging picture changes. While in all sites but Oakland there were significant increases $(\mathrm{p}<.10)$ in the proportion of respondents with earnings of $\$ 500$ a month (Figure 3), at 24 months rates of employment at SGA were very low: In six of the nine sites, they were less than $25 \%$.

Median monthly earned income among those employed at 24 months ranged from $\$ 333$ (Portland) to over $\$ 1,000$ (San Francisco and Stockton). In six of the nine sites (Chicago, Detroit, Seattle, San Jose, Los Angeles, and Oakland), it ranged from $\$ 380$ to $\$ 575$. In most places earned income was stable or increased gradually between the six-month and 24month follow-ups, but there were dramatic increases in Stockton and San Francisco. In Stockton, median earned income at 24 months was $\$ 1,067$, a hefty increase from previous waves, for which it ranged from $\$ 184$ to $\$ 584$. In San Francisco, earned income was $\$ 297$ at six months, $\$ 1,179$ at 12 months, $\$ 600$ at 18 months, and $\$ 1,155$ at 24 months. This volatility is an artifact of the small number of employed San Francisco respondents in the no-income-assistance category, which varied from eight at the six-month follow-up to 11 at 24 months. 


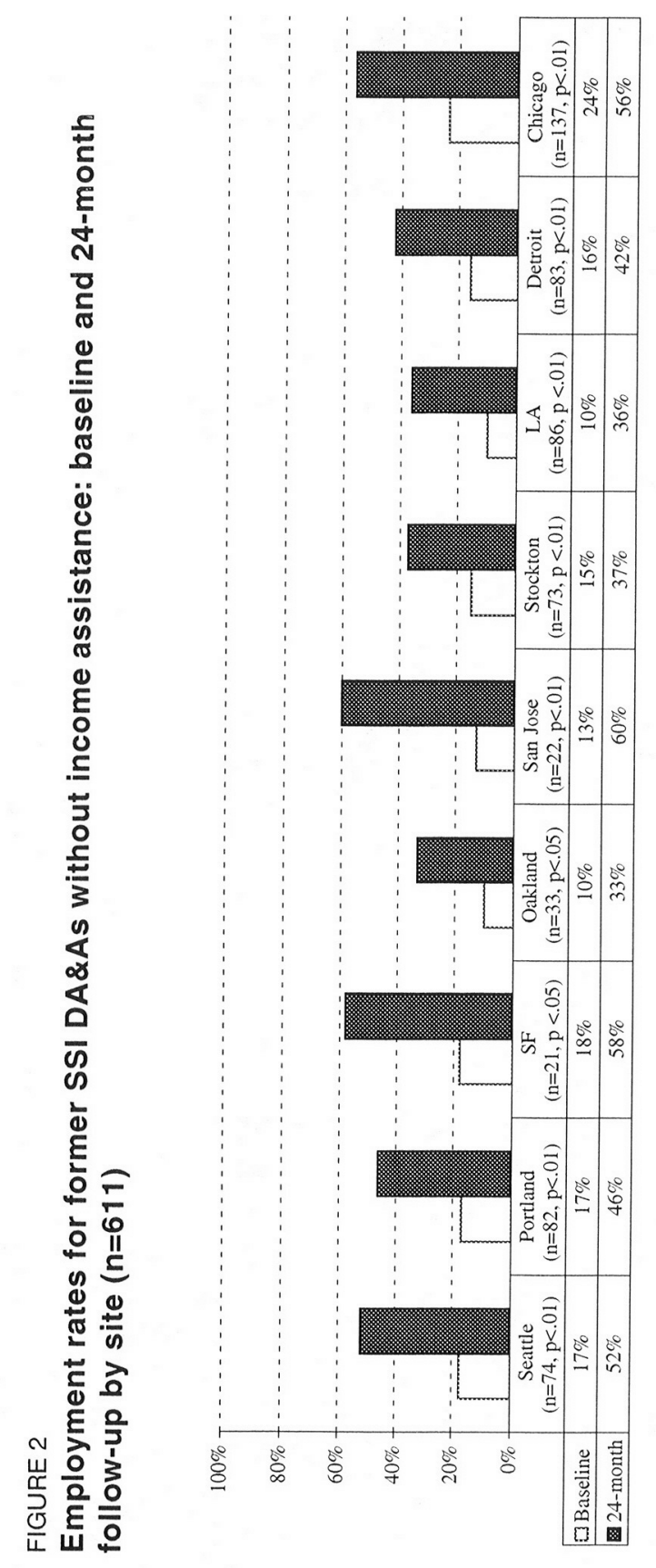



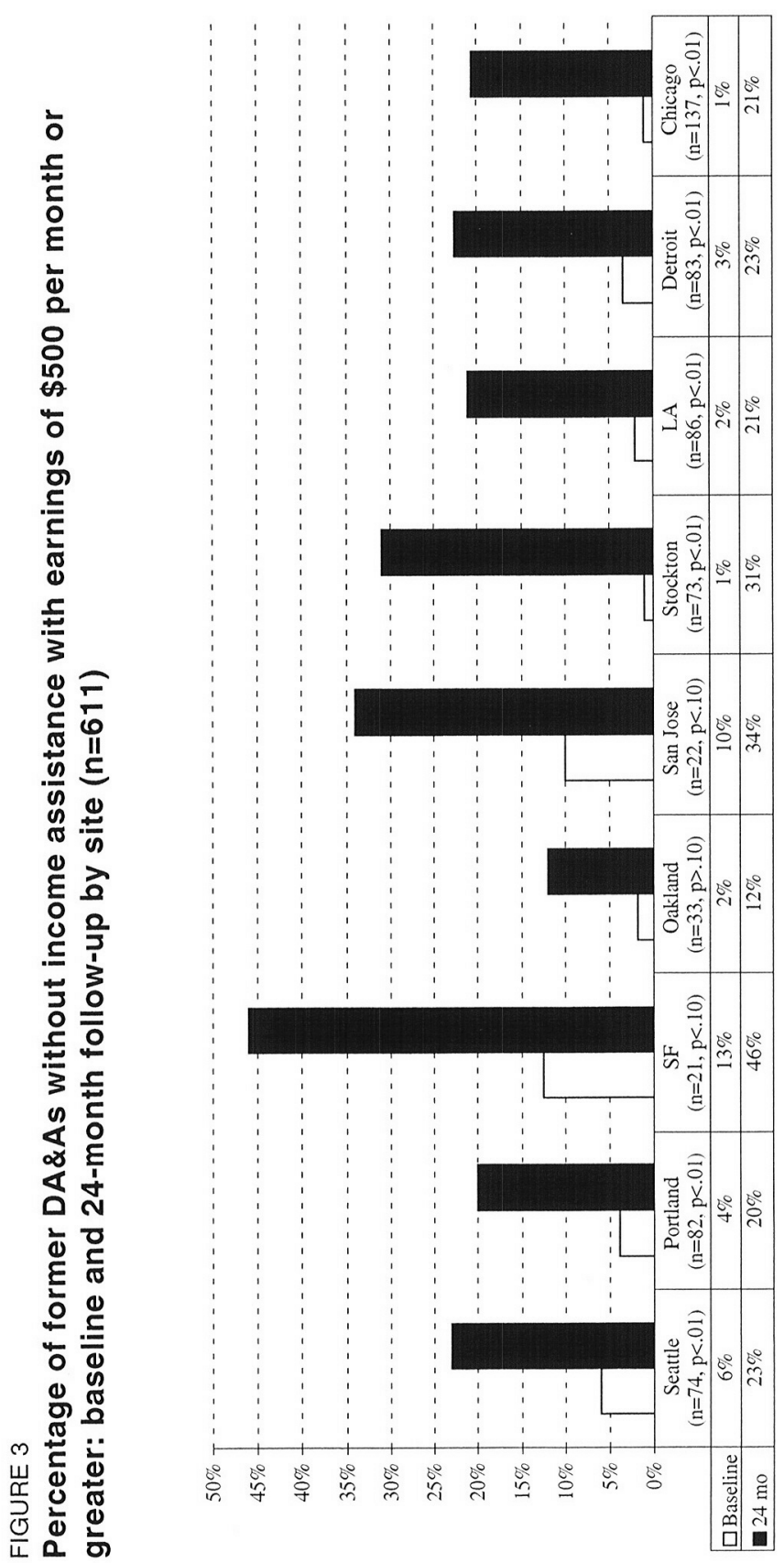

Reproduced with permission of the copyright owner. Further reproduction prohibited without permission. 
To put such earnings in perspective, it is useful to view them against a measure of the cost of housing. Figure 4 shows the 24-month median monthly earned income of former DA\&A recipients as a percentage of the 1998 Fair Market Rent (FMR) for a studio ("efficiency") or one-bedroom apartment in each site. These percentages are based on the FMR for a studio except for respondents who reported living with a minor child, in which case we used the one-bedroom FMR.

For their housing to be minimally affordable, our respondents should earn at least $200 \%$ of FMR. Even at that level they would spend $50 \%$ of gross income on rent, a figure substantially higher than the federal standard of $30 \%$ of adjusted income used to set rents in public housing during the study period. They would, in short, remain "shelter poor," having little income left for other needs (see Stone, 1993). As Figure 4 illustrates, everywhere but Stockton fewer than $40 \%$ (range $18 \%-36 \%$ ) earned $200 \%$ of FMR. A similar proportion ( $28 \%-40 \%$ everywhere but Stockton and San Francisco) earned less than $50 \%$ of FMR. In sum, in most sites few employed former DA\&A recipients could minimally afford even a tiny apartment, usually of the one-room variety.

Patterns of Everywhere but Oakland and Detroit, at least $30 \%$ of former employment

Stability of employment

DA\&A beneficiaries reported some employment earnings at the majority of follow-ups they completed. In our terminology, they were "usually" employed. However, we should not make too much of what we call usual employment, as the case of the Portland woman discussed below will illustrate. The semistructured interviews suggest that among those usually employed, many did only minimum-wage temp work or chased odd jobs cleaning houses and offices, repairing and painting things for neighbors, doing telephone sales once in a while, or, in one case, calling Bingo in a tavern two nights each week.

Among those who became employed after baseline, 59\% across sites reported income from work six months after their 


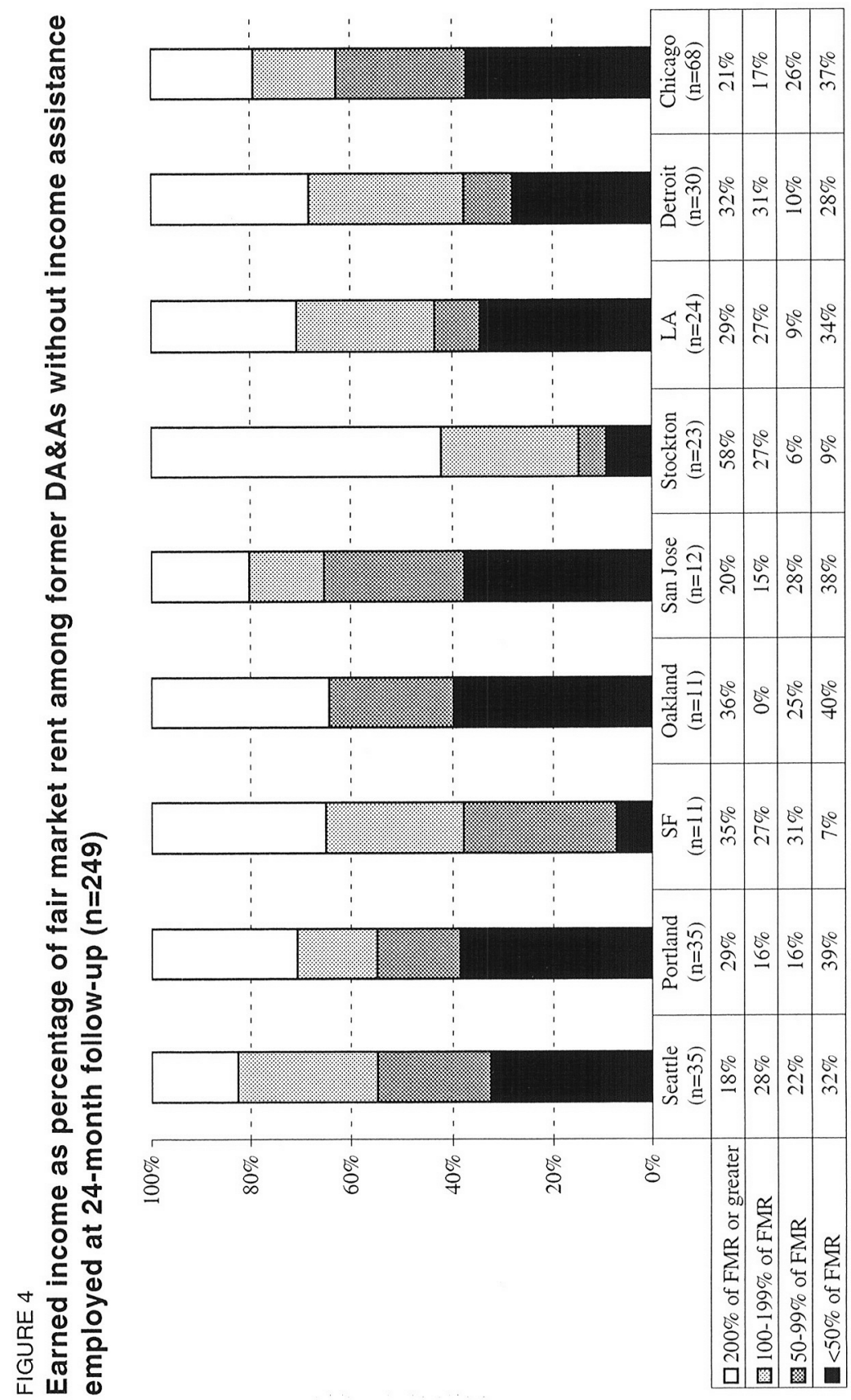


first such report. Only Detroit's work retention rate (40\%) was significantly $(p<.05)$ lower than average. ${ }^{12}$ Recall, though, that this rate is based on a report of any work in the 30 days prior to the index interview and the same kind of report in the following interview. Several sorts of errors involving the structured interviews' temporal blind spots and our definition of employment might cause this indicator to underestimate or overestimate work retention. Using the semistructured interviews to test these, we found no case in which an ill-timed loss of work, for example, resulted in an underestimate of job retention. However, we found that of those we call "new" workers, many had only widely spaced odd jobs and yet appeared continuously employed on that basis. A young Portland woman is a good example. She worked a total of 10 hours off-book doing housecleaning and occasional, irregular hours at telephone sales in the month prior to wave 2 , and two weeks full-time conducting a houseto-house survey in the month before wave 3 . This was the only work she had between July 1996 and March 1998; yet by our definition, she retained employment for six monthsin fact, for the whole of 1997. In view of such cases, we think our work retention rates, low as they are, greatly overstate continuity of employment.

Stability of Few former DA\&A recipients achieved SGA on a regular earnings at the

SGA Level basis: Generally, fewer than 20\% reported earnings of $\$ 500$ a month or more at the majority of follow-ups. In six of the nine sites (Seattle, Portland, Oakland, Los Angeles, Detroit, and Chicago), $15 \%$ or fewer were "usually" employed at SGA (see Figure 5). Even at the level of SGA, however, caveats about the quality of our respondents' work remain in order. In 1998, SGA could be achieved with only 21.5 hours of minimum-wage work each week in Washington, Illinois and Michigan, 19.5 hours in California, and 18.5 hours in Oregon. To be sure, some who regularly earned SGA had good jobs: In the semistructured interviews, we talked with a union shipyard worker in Portland, a union construction worker in 

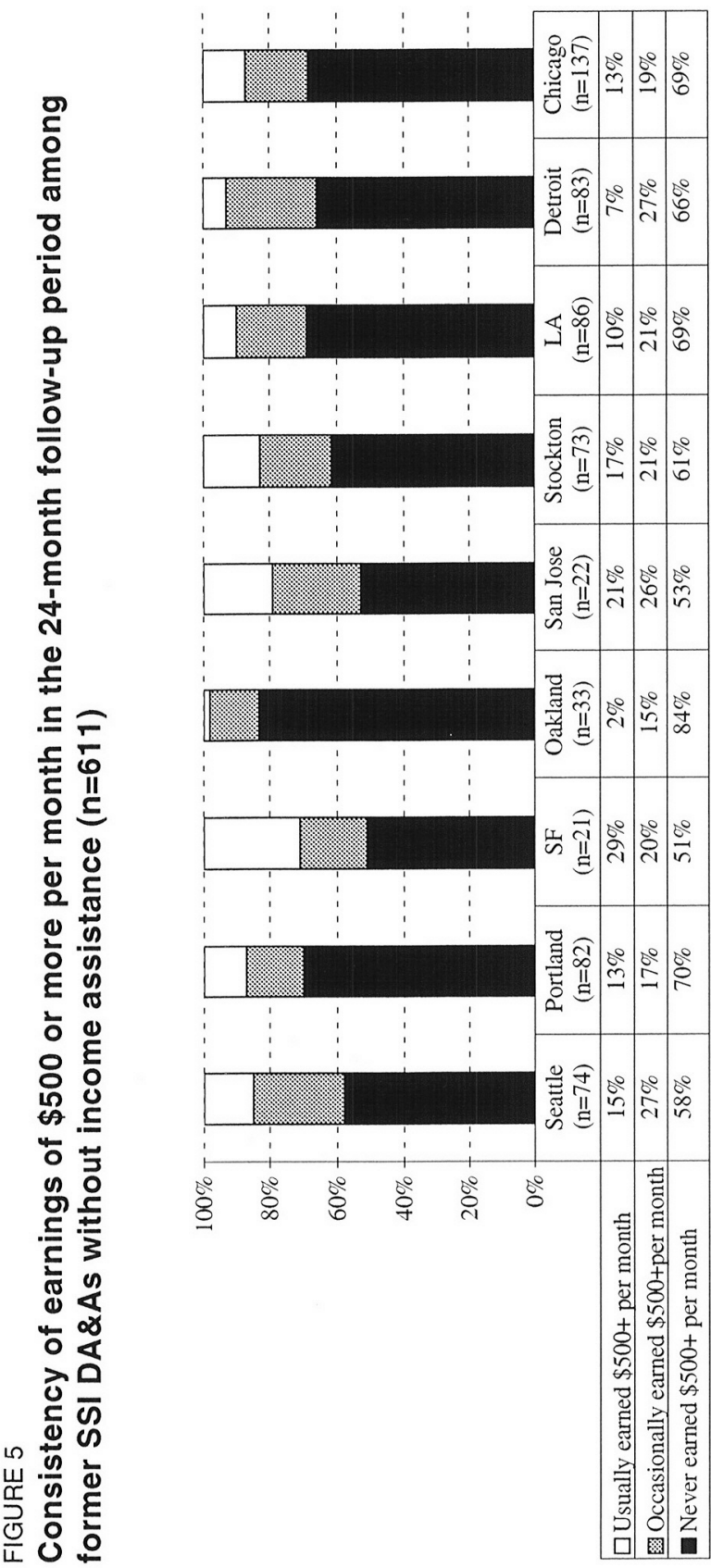
San Francisco, an addiction counselor in Stockton, and a welder in Chicago. They made living wages and saw futures for themselves. But they are outliers in the distribution of earned income reported above.

Independent Indicators of employment stability were significantly correpredictors of employment outcomes lated with employment status at baseline and baseline abstinence from alcohol and illegal drugs. Among the employed, employment status at baseline was correlated with later earned income.

Employment Status at Baseline: In Chicago, among former DA\&A recipients not employed at baseline $(\mathrm{n}=103)$, only $38 \%$ were usually employed during the follow-up period. By contrast, among those already working at baseline $(\mathbf{n}=32)$, this figure was $69 \%(\mathrm{p}<.05)$. In Los Angeles, among those unemployed at baseline $(n=75)$, only $21 \%$ were usually employed during the follow-up, whereas among those working at baseline $(\mathrm{n}=11)$, this figure was $76 \%(\mathrm{p}<.05)$. Across all other sites, these figures were $24 \%(n=329)$ and $52 \%$ $(\mathrm{n}=58)(\mathrm{p}<.05)$.

Similarly, among those unemployed in Chicago at baseline $(n=103)$, only $7 \%$ usually achieved SGA, whereas $30 \%$ of those working at baseline $(n=32)$ usually earned $\$ 500$ per month $(p<.05)$. In Los Angeles as well, only 5\% of those unemployed at baseline $(n=75)$ usually achieved SGA, whereas $53 \%$ of those working at baseline $(n=11)$ usually did so $(p<.05)$. Across all other sites, these figures were $9 \%$ $(\mathrm{n}=329)$ and $23 \%(\mathrm{n}=58)(p<.05)$. We take up employment barriers below; but here we should note that a combined-site analysis revealed, not surprisingly, that at all waves those employed at baseline had fewer barriers to employment than those not working at baseline.

Finally, monthly median earned income was $\$ 289$ for those in Chicago employed at 24 months but not at baseline $(n=48)$, compared with $\$ 497$ among those working at both baseline 
and 24 months $(n=19)$. Across all other sites, these medians were $\$ 513(n=138)$ and $\$ 742(n=43)$. In short, while monthly median income rose over time, the value accruing to baseline employment remained.

Substance Use: We found a statistically significant $(\mathrm{p}<.05)$ relationship between baseline abstinence from alcohol and illegal drugs and the consistent performance of SGA in Chicago and Stockton, where 33\% (Chicago, $\mathrm{n}=31$ ) and 37\% (Stockton, $n=25$ ) of those abstinent in the six months before baseline "usually" achieved SGA during the study. In comparison, only $6 \%$ (Chicago, $n=106$ ) and $8 \%$ (Stockton, $n=48$ ) of those who drank or used in the six months before baseline usually made SGA. We found a similar relationship in Seattle, Portland, and Los Angeles, though it was not statistically significant. We will have more to say about this in the Discussion section, below.

Barriers Table 4 details the prevalence at 24 months of each of the to SGA eight barriers to employment for each of the sites included in

Prevalence of specific barriers this analysis. The prevalence of discrete barriers varied widely from place to place. Overall, transportation was the most common obstacle (55\%), followed by low levels of education $(53 \%)$, substance abuse $(32 \%)$, inadequate job skills $(31 \%)$, physical health problems $(25 \%)$, mental health problems $(13 \%)$, domestic abuse $(9 \%)$, and unstable housing $(8 \%)$.

In most sites, the number of barriers was fairly stable over time. In Chicago and Stockton, however, the proportion of respondents experiencing two or more barriers declined slightly between six and 24 months, dropping from $78 \%$ to $68 \%(p<.05)$ in Chicago and $75 \%$ to $58 \%(p<.05)$ in Stockton. With the exception of the job-skills and transportation impediments, the prevalence of specific barriers was similarly stable. The proportion of respondents indicating a need for help with job skills declined in Chicago (48\% vs. $33 \%$, $p<.01$ ), Seattle (52\% vs. $35 \%, p<.10$ ), Detroit (37\% vs. $24 \%$, 


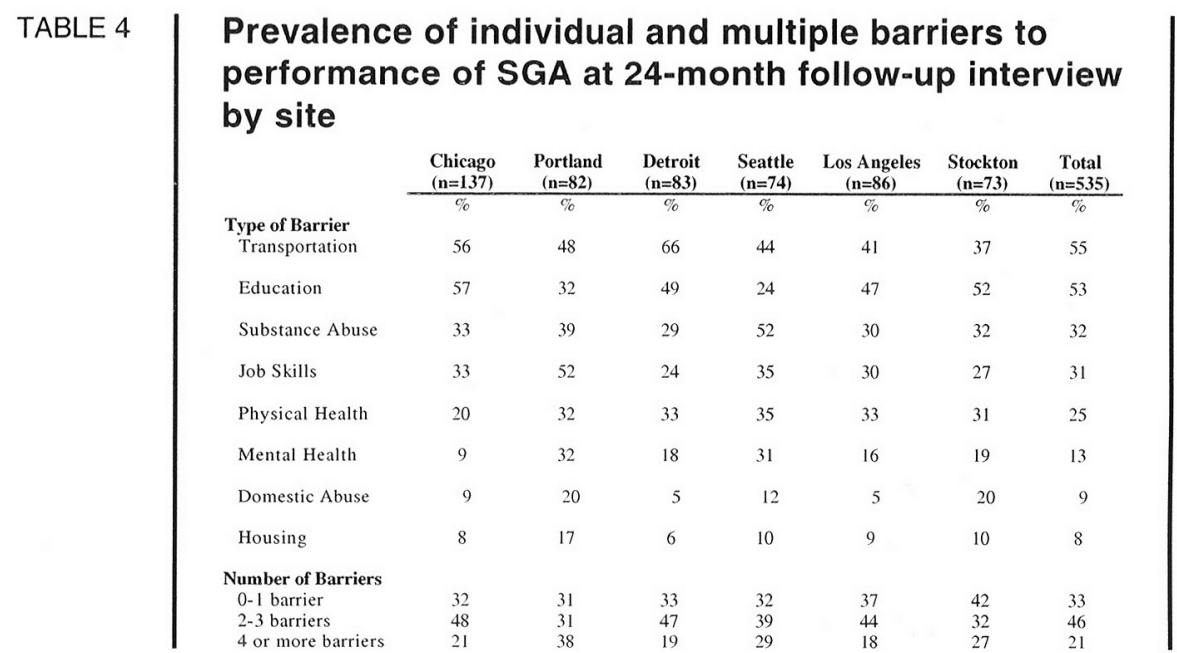

$p<.05$ ), and Stockton ( $38 \%$ vs. $27 \%, p<.10$ ). The proportion of respondents indicating a need for help with transportation declined in Chicago ( $73 \%$ vs. $56 \%, p<.01)$, Seattle $(61 \%$ vs. $44 \%, p<.05)$, Stockton $(63 \%$ vs. $37 \%, p<.05)$, and Los Angeles (60\% vs. $41 \%, p<.05)$.

Our data do not permit us to explain these changes with any confidence. The decline in reported need for job skills may in some part have resulted from training: In all sites but Seattle (where the figure was only 6\%), 17\%-29\% of those reporting a need for training at six months had received some by 24 months. However, the decline may also have been the result of employment, especially at the SGA level: Only $7 \%$ of those employed at SGA reaffirmed their need for training at 24 months if they had been unemployed at six months and indicated a need for training but did not get any. In contrast, $50 \%$ of those unemployed at 24 months reaffirmed the need for training expressed at six months $(p<.05) .^{13}$

Similarly, employment at SGA was associated with lower rates of reported transportation problems, but only in some sites. In Portland, 73\% of those not earning SGA at 24 
months reported transportation problems, whereas no one (0\%) earning SGA did so. Findings in Los Angeles (67\% vs. $0 \%$ ) and in Stockton (43\% vs. $0 \%$ ) were similar, though cell sizes were small in all these sites ("n's" ranged from 22 to 24). Earning SGA made no difference in Chicago, Detroit, or Seattle.

Relationship In five of the six sites examined (Seattle, Portland, Chicago, between the Detroit, and Stockton), the likelihood of achieving SGA number of barriers and $S G A$ increased as the number of employment barriers declined (Table 5). In Portland, for example, on average across waves, only $2 \%$ of respondents who experienced four or more barriers performed SGA. But among those experiencing two to three barriers, 9\% reached SGA (OR $=2.1, p<.01)$, and among those with zero or one barrier, $42 \%$ did so $(\mathrm{OR}=6.1$,

\section{Relationship between the number of barriers and performance of SGA by site}

\begin{tabular}{|c|c|c|c|c|c|}
\hline & \multirow{2}{*}{$\begin{array}{c}\% \text { employed at } \\
\text { SGA level }\end{array}$} & \multirow[t]{2}{*}{ Odds Ratio $^{\mathbf{b}}$} & \multicolumn{2}{|c|}{$95 \% \mathrm{CI}$} & \multirow[t]{2}{*}{ p-value } \\
\hline & & & Low & High & \\
\hline \multicolumn{6}{|l|}{ Seattle $(n=74)$} \\
\hline 4 or more barriers & 7 & Reference & & & \\
\hline 2-3 barriers & 14 & NS & & & \\
\hline $0-1$ barrier & 47 & 8.8 & 2.3 & 32.2 & $<.01$ \\
\hline \multicolumn{6}{|l|}{ Portland (n=82) } \\
\hline 4 or more barriers & 2 & Reference & & & \\
\hline 2-3 barriers & 9 & 2.1 & 1.3 & 3.5 & $<.01$ \\
\hline $0-1$ barrier & 42 & 6.1 & 3.1 & 11.9 & $<.05$ \\
\hline \multicolumn{6}{|l|}{ Chicago $(n=137)$} \\
\hline 4 or more barriers & 3 & Reference & & & \\
\hline $2-3$ barriers & 10 & 1.9 & 1.1 & 3.1 & $<.01$ \\
\hline 0 - 1 barrier & 34 & 5.8 & 2.8 & 11.9 & $<.05$ \\
\hline \multicolumn{6}{|l|}{ Detroit $(\mathrm{n}=83$ ) } \\
\hline 4 or more barriers & 7 & Reference & & & \\
\hline $2-3$ barriers & 11 & NS & & & \\
\hline 0 - 1 barrier & 21 & 3.2 & 1.4 & 7.4 & $<.05$ \\
\hline \multicolumn{6}{|l|}{ Stockton $(n=73)$} \\
\hline 4 or more barriers & 4 & Reference & & & \\
\hline $2-3$ barriers & 12 & 2.5 & 1.2 & 5.2 & $<.01$ \\
\hline $0-1$ barrier & 41 & 7.3 & 3.2 & 16.4 & $<.05$ \\
\hline \multicolumn{6}{|l|}{ Los Angeles ( $n=86)$} \\
\hline 4 or more barriers & 9 & Reference & & & \\
\hline $2-3$ barriers & 17 & NS & & & \\
\hline $0-1$ barrier & 30 & NS & & & \\
\hline
\end{tabular}


$p<.05$ ). We found a similar pattern in Chicago and Stockton, and to a lesser degree in Seattle and Detroit.

Individual Individual barriers significantly $(p<.05)$ correlated with perbarriers forming SGA are detailed in Table 6. Transportation probsignificantly correlated with $S G A$ lems were significantly correlated with SGA in five of the six sites. Respondents with a transportation barrier were 2.0-4.5 times less likely to be achieving SGA than those without one. Everywhere but in Los Angeles and Detroit, respondents with more severe substance abuse problems were 1.8 (Chicago) to 3.4 (Seattle) times less likely to be employed at SGA. In all sites except Los Angeles and Detroit, low job skills significantly reduced the likelihood of achieving SGA. Respondents reporting a need for help with job skills were 1.8 (Chicago) to 3.1 (Stockton) times less likely to earn SGA. Respondents with more severe mental health problems were less likely to be employed at SGA in Seattle (OR = 2.6), Stockton (OR = $2.9)$ and Chicago $(\mathrm{OR}=2.1)$. Those with more severe physical health difficulties were less likely to earn SGA in Chicago $(\mathrm{OR}=2.6)$ and Detroit $(\mathrm{OR}=2.2)$.

\section{Barriers independently correlated with non- performance of substantial gainful activity by site}

\begin{tabular}{|c|c|c|c|c|c|c|}
\hline & $\begin{array}{l}\text { Seattle } \\
(\mathrm{n}=74)\end{array}$ & $\begin{array}{c}\text { Portland } \\
(\mathrm{n}=82)\end{array}$ & $\begin{array}{l}\text { Chicago } \\
(n=137)\end{array}$ & $\begin{array}{l}\text { Detroit } \\
(\mathrm{n}=83)\end{array}$ & $\begin{array}{c}\text { Stockton } \\
(\mathbf{n}=73)\end{array}$ & $\begin{array}{c}\text { Los } \\
\text { Angeles } \\
(\mathrm{n}=86)\end{array}$ \\
\hline & $\begin{array}{l}\text { Odds } \\
\text { Ratio }^{2}\end{array}$ & Odds Ratio & Odds Ratio & Odds Ratio & Odds Ratio & Odds Ratio \\
\hline $\begin{array}{l}\text { Type of Barrier } \\
\text { Transportation }\end{array}$ & 3.5 & 4.5 & 3.4 & 2.0 & 3.2 & NS \\
\hline Job Skills & 2.7 & 2.3 & 1.8 & NS & 3.1 & NS \\
\hline Substance Abuse & 3.4 & 2.9 & 1.8 & NS & 2.6 & NS \\
\hline Mental Health & 2.6 & NS & 2.1 & NS & 2.9 & NS \\
\hline Physical Health & NS & NS & 2.6 & 2.2 & NS & NS \\
\hline
\end{tabular}




\section{Discussion}

Summary and interpretation of the findings
Our data tell a story about widespread unemployment and sub-employment in the midst of an extraordinarily tight labor market. While rates of any employment (earnings of even one dollar in the previous month) increased substantially after baseline, at the 24-month follow-up fewer than $25 \%$ of our respondents earned $\$ 500$ per month or more. Former DA\&A recipients who worked by and large failed to earn their way out of extreme poverty: Across sites, only a small percentage $(12 \%)$ "usually" earned the $\$ 500$ per month necessary to replace the cash value of SSI, and most earned far less than required to minimally afford the most modest sort of housing. It should not be surprising, then, that Norris and her colleagues (this issue) found substantially elevated rates of residential doubling-up and literal homelessness among respondents who lost SSI benefits.

Like other analysts of welfare-to-work dynamics, we found that our respondents had a variety of work impediments, and that the more they had, the more poorly they fared in the labor market. Our findings are roughly equivalent to those in the rapidly accumulating literature on TANF, which finds various constellations of work barriers pertaining to both environmental obstacles (notably transportation) and limitations of human capital (particularly education). It would be unwise to go beyond this simple generalization. The characteristics of welfare populations are administrative artifacts in that they derive from the eligibility criteria of specific programs. While welfare populations may share some barriers to work (such as low levels of educational achievement and vocational skills), others are particular to the group assembled under a specific administrative category. For example, child-care problems, which we did not measure, are more likely to constitute a work barrier for TANF parents than for former SSI DA\&A beneficiaries. On the other hand, our semistructured interviews suggest that prison experience (unmeasured by the 
structured interviews) may be a significant work barrier among former DA\&A recipients: 30 (41\%) of the 73 semistructured interview respondents in the no-income-assistance category spent time in a state or federal prison. Of these 30, six had also been in the California Rehabilitation Center (CRC) for drug offenders, three had been committed to a state forensic psychiatric facility, and one had been in a state prison, a forensic psychiatric hospital, and CRC. ${ }^{14}$

Although our results varied somewhat by place, we found employment barriers related to substance abuse and mental and physical health that would be expected in an impoverished, middle-aged population composed in large part of long-term drug addicts and alcoholics. The prevalence of the substance-abuse barrier was not higher, because, contrary to conventional wisdom, quite a few former DA\&A recipients were not drinking or using heavily when the program ended. Indeed, at baseline, across sites, $22 \%$ of those without income assistance reported no use of alcohol or illegal drugs during the previous six months. ${ }^{15}$

For all our emphasis on poor employment outcomes, we must also ask why a small percentage of former DA\&A recipients did manage to "get up in the morning and support themselves," to invoke Representative Shaw's words once more. There appear to be three related components of what must be a somewhat speculative answer.

The first is economic context. When the demand for labor is sufficiently great and expectations of productivity are sufficiently flexible, people with all sorts of serious impairments can work. During the economic recovery of the Preparedness Era preceding World War I and the subsequent military absorption of tens of thousands of men, admissions to public residential treatment facilities for alcoholism and drug addiction declined dramatically (Baumohl and Tracy, 1994). With the maturation of the Great Depression, admissions rose sharply, only to decline precipitously once more with Amer- 
ica's entry into World War II. By late 1942 there was so little slack in employment that the Kaiser Shipyards in Richmond, California, recruited a busload of "winos" from the Los Angeles County Jail to be trained as welders in lieu of their 90-day sentences (Hopper and Baumohl, 1996). Indeed, the necessity to make do with such erratic employees led to the first workplace alcoholism programs during World War II (White, 1998). Our findings probably reflect a similar (if less dramatic) influence: Some former DA\&A recipients found regular work because, in the midst of the most sustained economic expansion of the post-war era, some jobs requiring modest skill and experience were available, and some employers, at least, were willing to take on employees with large gaps in their work histories and other significant blemishes. ${ }^{16}$ Economic context may also explain why the relationship between the number of employment barriers and the achievement of SGA in Detroit, while significant, is not as strong as in other sites: Where jobs are in short supply and a person has any fundamentally discrediting characteristic or environmental obstacle, additional impediments are unlikely to matter.

Second, as we saw in Chicago and Stockton (and perhaps in Seattle, Portland, and Los Angeles-the relationships in these small samples fell short of statistical significance), a period of established sobriety facilitated the regular achievement of SGA. This said, however, we should not expect sobriety and regular SGA to be neatly correlated: Just as sober folks can be chronically unemployed or underemployed, some jobs accommodate heavy drinkers and drug users. A heavy-drinking Stockton native, a man in his mid-40s, described his ideal job as that of "a maintenance man in a large park . . . keeping the grass clean and green and keeping the roads clean, and working at your own pace, but no contact with people." At one time-now at least two generations past - there were many opportunities for the stubbornly dissipated to redeem their time by such isolated labor: Snow, leaves, and garbage 
long were removed by men (usually) of persistent "unsteady habits," to use an old expression. This Stockton fellow despaired of ever having such a good bad job ("You have to have 20 years of college in order to even apply for them anymore"); but a Portland man a few years older, and no more sober or sociable, fell into one just like it with the ending of the DA\&A program. It even came with benefits.

Third, those who regularly achieved SGA reacted to the threat of lost benefits by quickly looking for work even if they pursued an SSI redetermination or appeal at the same time. Significant employment gains typically were realized in the first six months of the study. Across sites, of those already working at baseline, $29 \%$ usually achieved SGA over the study's course, as opposed to only $7 \%$ of those not working at baseline. Even if their initial employment was modest, some of these respondents were able to increase their hours or get better jobs: Among those working at baseline, only $11 \%$ earned SGA at that point; however, two years later $57 \%$ of those still employed were making SGA.

But most former DA\&A recipients working at baseline did not consistently earn SGA. If the semistructured interviews are reliable guides, most had only occasional work at baseline and had been doing spot jobs during much of their lives and their tenure on SSI. When the program ended, many got along by the haphazard sort of opportunity described by a middleaged Chicago heroin addict:

Yeah [I'm using], and I'm really in a pickle barrel, right? I'm busted [broke], I'm getting cut off. I'm living and I gotta spend $\$ 250$ a month [on rent] that I ain't got. Or soon not to have. . . . [So I] stretched up until I got cut off. Hammer came down and it was two months I lived free. Told the guy I'm gonna pay him, I'd pay him, I'd pay him. You know how that goes. And stayed there as long as I could. Finally, he threw me out. [So I went to another building.] The guy says, "Danny [not his real name], if you fix my building, you can live free." So he gave me one apartment that was heated and electric. Running water, of course, and everything. But I had to fix the building. Sweep it, clean out the hallways, repair win- 
dows. You understand what I'm saying? I was living free on that. He was paying me-like, he'd give me like maybe $\$ 50$ for the whole week, no money at all.

By contrast, for many of those who consistently earned SGA, looking for work immediately was an extension of their current or recent treatment experience. They defined SSI as a part of the past that needed to be shed, and sometimes they echoed the language of "enabling" frequently used by critics of the DA\&A program (see Hunt and Baumohl, $b$, this issue). Listen to a Portland man in his late 30s:

So they got all these flyers up in the treatment center. If you on SSI and you getting cut off, you can appeal-da-di-da, these numbers, representatives. So they having this big old push, I guess, trying to keep up with everybody now. I guess this about August, September [of 1996]. So I'm in treatment now. I don't want it [SSI] no way. You know what I mean? I'm glad they cutting it off, really, because I've come to the realization that this ain't did nothing but enable me to keep doing what I was doing. It's not they fault, it's mine, you know? . . . [W] hat did I need a job for? What do people have to work for? They work to pay bills and try to attain something in life, or become a member of society-all the things I never wanted to do anyway.

More typically, those in recovery praised the DA\&A program for the material support it offered when they most needed it, but allowed that they became "tired of waiting for the check," or recalled that they were getting restless and it had become "time to move on." Explained a 55-year-old San Francisco man working in human services: "Being in recovery and being, you know, clean, I wanted to try to do something on my own. I wanted to finally start trying to like get a job, become responsible and all that kind of stuff (laughs)."

Others, abstainers and users alike, immediately sought any kind of work because they were afraid and angry. "I was scared," confessed a San Francisco woman in her early $30 \mathrm{~s}$ who was working several part-time jobs when we spoke with her in April 1998. "I was scared because that money was pay- 
ing my rent. But I hustled my ass. All my hustling skills came back, and I was like-I was just praying a lot." Said a Portland methadone patient, a man in his 50s who had spent much of his life in prison: "I went to work. I got me a job and quick. I didn't mess around." He found part-time work that provided benefits and some security. He recognized his good fortune and expressed a view common among those who succeeded but felt driven into the labor market: "There's days I wished I was back on SSI. Because my back gives me hell. It does. But I'll never apply for it. I hated President Clinton for what he did, the way he did it so quick, you know. I'm sure a lot of them [former DA\&A recipients] do. But, actually, I came out better. I came out better."

Limitations of work and income indicators: the problems of barter and crime
While our generous indicators substantially overestimate meaningful employment, they allow us to say with confidence that former DA\&A recipients had very poor employment outcomes, even by standards that systematically overestimate success. But if we have overestimated more or less formal employment, we have underestimated other, employment-like arrangements. Barter and crime are the difficulties here, as the following two cases from the semistructured interviews illustrate.

A 50-year-old Chicago man explained his current employment this way: "This guy got a, he just opened up a restaurant. He call it a fish house. Okay, I can cook and stuff (chuckles; he's a large man). And then he got this little construction. . . . [H]e was doing roofing and stuff, too. So he had me cooking and working [and eating] in the restaurant. Now we got it started, me and him, so he tell me, "Well, I can't afford to pay you so and so." Okay, that's cool. But he owns some buildings, so he give me an apartment, a room, in one of the [apartments]."

A Stockton man of roughly the same age explained that he lived in a trailer on a farm owned by his elderly father. He did substantial chores in lieu of rent. But he also needed cash 
to pay his utility bill and support his heroin habit. For this, he occasionally worked for a friend who painted houses, and he kept a small heroin trade for "old timers, you know, people who been shooting dope for 20,30 years. . . just people I've known forever." He added: "I don't make anything. . . but it cuts the cost."

The quantitative analyses in this paper treat these men as "usually" employed because each reported income from employment at the various waves. The Chicago man reported the $\$ 200$ or so he was paid each month for the occasional day spent roofing, framing, or hanging drywall; the Stockton man reported the similar amount of money he earned painting houses with his buddy. But the structured-interview data don't capture the value of the Chicago man's room and board, and they miss the Stockton fellow's chores-for-housing arrangement and his income from drug dealing.

We think such omissions were common. Family relationships, in particular, seriously complicate definitions of work and income. Because exchanges among kin exist outside the market relationships that define terms such as wages, rents, and loans, respondents often struggled to characterize how they made ends meet. Like the Stockton man on his father's farm, respondents who lived continuously with family typically considered doing chores to be courteous "helping out" when they paid rent but as barter or familial duty when they didn't. These are important but subtle distinctions not captured by the structured interviews. Sometimes a family strategy to keep a dependent relative useful, or at least feeling useful, was reported in the structured interviews as employment, sometimes it was called a "gift" or a "loan," and sometimes it simply went unremarked. A 35-year-old woman born and raised in Stockton, and surrounded by her large family, attended elderly kin and cleaned house for other relatives who gave her money "every now and then." This income was not reported in any of the structured interviews. In Chicago, a man in his late 40 s was absorbed into a family construction 
business in such a way that his pay stayed with kin: His son employed him one day a month for a very generous sum so that he could pay rent to the son's aunt (the man's sister). The man wasn't fooled ("The work I do for him ain't worth $\$ 200$ or $\$ 300 ")$, but he appreciated the gesture. In the structured interviews, he reported the money in the spirit in which it was given: as employment earnings. Similarly, in the words of another Chicago man nearing 50, a long-time heroin addict who reported only small amounts of income, mainly from donating blood and scavenging brass and copper fittings from abandoned buildings: "[My family] trusts me, they love me, they have me to their house, I stay over, I watch their kids. They pay me a little money, I clean their yards, 1 cut their grass. They lend me a little money . . . knowing I can't pay them back." Finally, a Portland woman indicated at 12 months that she had sold drugs during the previous six months, but she reported no income from it. In the semistructured interview she clarified this response: "I help my sons a lot," she said. "Every day." Her support came in part from such "help," but she would not characterize it as wage earning, nor could she quantify her "draw" on the family drug business.

Because we think that even many of those who reported income from crime gave estimates that were substantially in error (probably on the low side), we did not treat criminal income in a systematic fashion in our quantitative analyses. Prevarication is not the issue, or at least not the main one. Rather, respondents who hustled their livelihoods found it very difficult to specify their income after the fact. In the semistructured interviews, we found that some criminal behavior was sufficiently discrete and infrequent that respondents could report relatively precise amounts of income. The prostitute who worked only occasionally, for example, could often provide a confident estimate. ${ }^{17}$ But the hustling poor are a versatile lot, doing a little of this and a little of that in a complicated stream of economic activity not easily reckoned 
(see Hopper et al., 1985; Snow et al., 1996). A Portland man said: "I might cash [forge] a check, or I might show somebody how to cash a check and get a piece of money or something like that. Or, you know, if somebody wants a certain amount of drugs and I know where to get it, I'll get-like I said, some from both ends." While drug selling among our respondents was most often like that of the Stockton farmer's son-a matter of "dealing for stash," where, if he bothered, a dealer might figure a rough profit as a percentage of his habit subsidized-for some the drug business involved many transactions over a day in which the dealer's capital and the customers' payments were commingled and bookkeeping was further complicated by payments in kind, complimentary "tastes," payments to lookouts and go-betweens, and the dealer's own consumption. "Sometimes I'm out on the street," a 30-year-old Chicago man said, "and the money flows through my hands. I mean, you have to be there to see it. It's hard to explain . . . I mean, when you're out there money flows through you." He claimed to handle thousands of dollars on a good day. "I can pocket $\$ 500$, as long as I don't shoot it up or smoke it up," he said-but allowed that this happened rather often.

It is impossible to adjust our quantitative analyses to account for such ambiguous economics. ${ }^{18}$ They are an inevitable part of the background noise. It seems certain, though, that if hustling profits were included, many more of our respondents would have reached SGA. ${ }^{19}$

\section{Conclusion}

Even in the best of times, few former DA\&A recipients replaced their lost SSI income with earnings from work. Moreover, the rising rate of meaningful employment in this population stalled a year after baseline, suggesting that outcomes are not likely to improve. While a small number made 
a successful transition from welfare to work, even their success could be precarious. Shipyard and construction workers face seasonal idleness; none of the public-sector workers with whom we spoke were permanent employees, and thus none had benefits.

Consider the situation of a San Franciscan we'll call John. John collected SSI for less than two years before the DA\&A program ended, qualifying shortly after his last parole from prison in 1995. In April 1998, after more than 30 years of heroin addiction and intermittent incarceration, he had been successful with methadone for two years and had a full-time job at nine dollars an hour, grossing over $\$ 1,500$ monthly. He lived with his girlfriend of 10 years in a hotel room for which they paid only $\$ 380$ per month. His girlfriend received $\$ 370$ each month in General Assistance and $\$ 81$ in food stamps. On the surface, and relative to most former DA\&A recipients, John had it made-yet he was a very worried man. His job provided no medical, pension, or vacation benefits. It required him to have a car, which meant paying for insurance, parking, and maintenance. With his girlfriend, a woman in her mid-40s, he had two young children who, because of her drinking and heroin addiction, had been placed by child welfare authorities shortly after John went to prison in 1994. Now that they were both settled in a methadone program, and with John's parole nearing an end, they looked forward to getting their kids back. But this would mean a larger place, requiring probably double their current rent. Moreover, his income would disqualify the family for TANF benefits, although Medicaid (Medi-Cal) would continue for his children. Indeed, now that he was working, his Medi-Cal had been stopped, and the county had sent him a $\$ 1,250$ bill for his last five months of methadone. "They just got me in one hell of a bind right now," he said angrily. "All of a sudden, bam! I had all my teeth pulled on Medi-Cal. I was gonna get plates and all that. Now this is all out of my pocket. . . . My cholesterol is high. I have high blood pressure. I got blood in 
my urine. . . . I got hepatitis. . . . I'm gonna be $56 . .$. . And how much longer can I work? . . . There's gonna be nothing in retirement. So I'm gonna be back on SSI."

Athough most former DA\&A recipients are younger than John, the majority are in or entering midlife with little education, few skills, and many liabilities. Most who are working have jobs far less remunerative or regular than John's, and they face employment prospects that will not improve with time. Thus a lot of them figure to become reacquainted with SSI, as John foresaw for himself: Many who live long enough and don't spend their golden years in prison will, at 65, qualify for SSI on the basis of impecunious old age rather than disability. When all is said and done, that may be the bottom line.

Notes 1. The policy change also affected recipients of Social Security Disability Insurance (DI). The figure of 167,000 represents the number of people getting only SSI on the basis of an impairment "materially related" to alcoholism or drug addiction (about 120,000) plus "concurrent beneficiaries," those getting both SSI and DI on this basis (see Hunt and Baumohl, $a$, this issue, for an explanation of this status). Including those collecting only DI, 209,000 recipients were affected.

2. It is tempting to attribute this drop to a tightening labor market, because AFDC rolls had been in decline for several years before TANF was phased in beginning in August 1996. However, during the same time the value of the Earned Income Tax Credit (EITC) for the working poor was rising significantly, and many states already were operating TANF-like programs under federal waivers granting exemptions from AFDC rules. These waiver "experiments," like many subsequent TANF programs, diverted many applicants into job-search activities and eliminated from the rolls families who were not compliant with new administrative requirements. Thus the decline in the AFDC and TANF rolls represents a complex interaction of labor market conditions, EITC incentives, and welfare-towork incentives and sanctions. For a detailed consideration of these issues, see Ellwood (2000).

3. An early study of DA\&A beneficiaries (SRA Technologies, 1986), conducted before the explosion of the rolls in the 1990s (see Hunt and Baumohl, $a$, this issue), concluded that the population had little 
employment potential because of its members" poor physical and mental health, limited education, spotty work histories, and advanced age (almost half were 50 or older). This was a younger group by the time the program ended 10 years later, but other significant characteristics seem not to have changed dramatically.

4. Based on data from interviews conducted in 1989, Schmidt et al. (1998) found that GA recipients in a northern California county were about three times as likely to be problem drinkers and heavy drug users, and about four times as likely to have "substance dependencies," as AFDC beneficiaries. AFDC recipients had problem-drinking rates comparable to those of the county's general population, but they were more than three times as likely as general-population members to be heavy drug users or to meet criteria for alcohol or drug dependence.

5. A respondent was considered to have "lost her job" if she lost a job and did not find another within one month.

6. In July 1999, six months after we completed data collection, the SGA level was raised to $\$ 700$ per month.

7. The quotation is from one of the semistructured interviews that supplemented the scripted interviews. These are described below.

8. Sweeney (2000:14) reached the same conclusion: The "disabilities" that most TANF parents reported "do not meet the stringent tests of the SSI program." Similarly, the Michigan GA data suggest that while many recipients "were not able-bodied," their impairments did not meet SSI standards of disability (Henly and Danziger, 1996:221).

9. "Welfare recipients" were defined as "persons who report living in a household that received AFDC, public assistance, or public welfare in the past 12 months."

10. Under complicated work-incentive rules that do not warrant summary here, SSI beneficiaries may earn over $\$ 1,000$ per month for 12 months without jeopardizing their eligibility. Thus our finding that a small percentage of requalified former DA\&A recipients were working is neither surprising nor evidence of welfare fraud.

11. Because California provides a substantial state supplement to the federal SSI payment, the cash replacement value of SSI in the California counties is actually about $\$ 600$ per month. To avoid confusion, however, we used the federal minimum for all sites. When we ran analyses at the higher standard for the California counties, our findings were essentially unchanged.

12. In spite of this, the aggregate rates of any employment reported above remained relatively unchanged after six months because (1) 
over $50 \%$ of those who lost work between six and 18 months regained some employment by the end of the study and (2) respondents became employed for the first time at different points in the follow-up period: Initial employment came at six months for $55 \%$, at 12 months for $21 \%$, at 18 months for $12 \%$, and at 24 months for $11 \%$. Reemployment and the continuous addition of first-time workers thus stabilized the rates over time.

13. Among those employed at the study's end, income was related to a persistent expression of the need for skills training. Across sites, median income for those restating such a need was $\$ 187$ per month, compared with $\$ 490$ for those who reported no need. This trend was most apparent in Chicago (\$484 vs. \$193), Portland (\$627 vs. \$98), and Detroit ( $\$ 593$ vs. $\$ 236$ ).

14. Overall, $57(37 \%)$ of 156 semistructured-interview respondents spent time in one or another of these institutions.

15. The figures for six-month abstinence among people with no income assistance were highest in San Jose (56\%), San Francisco (35\%), and Stockton $(31 \%)$; the lowest rate was in Seattle $(14 \%)$. Some of the semistructured-interview respondents had been abstinent for several years. In some cases these were people with very serious impairments quite apart from any substance abuse (spinal injuries, for example), and they requalified for SSI as a result. Many of the long abstinent in the no-income-assistance group used SSI to supplement low-wage labor or to support their "recovery work." As Hunt and Baumohl discuss ( $a$, this issue), their continuing presence on the rolls was facilitated by the huge backlog of continuing-disability reviews in the DA\&A program.

16. These stigmata could be quite literal: Several semistructured-interview respondents discussed the problem of looking for work with gang-related or "politically incorrect" tattoos.

17. One Stockton woman was an especially devout accountant: As technically required, she once reported her sex-work earnings to the Social Security Administration, which dutifully docked her check for the amount over the allowable SSI income limit.

18. By repeatedly interviewing respondents and by encouraging them to save pay stubs and receipts, Edin and Lein (1997) made a heroic effort to document the income and expenditures of 214 welfare mothers in four American cities. Their method was not feasible in this study. Further, drinking and drug use created some reporting problems in their study-problems that likely would have been worse in ours.

19. Some of these criminal enterprises were of long standing. Had the Social Security Administration been aware of them, some of these 
people would not have qualified for SSI in the first place - at least not by the SGA rules instituted in 1995 (see Hunt and Baumohl, $a$, this issue).

Allison, Paul, Logistic Regression Using the SAS System: Theory and Application (Cary, NC: SAS Institute), 1999.

Baumohl, Jim and Sarah W. Tracy, "Building Systems to Manage Inebriates: The Divergent Paths of California and Massachusetts, 1891-1920," Contemporary Drug Problems, 21 (1994), 557-597.

Brauner, Sarah and Pamela Loprest, "Where Are They Now? What States" Studies of People Who Left Welfare Tell Us," The Urban Institute, Series A, \#A-32, May 1999.

Choudhry, G. Hussain and Cynthia Helba, "Rationale and Procedures for Weighting the SSI Study Data," Contemporary Drug Problems, 30 (2003), 137-146.

Congressional Budget Office [of the United States], Estimate of HR4, The Family Self-Sufficiency Act of 1995 (Washington, DC: Author), 1995.

Danziger, Sandra, Mary Corcoran, Sheldon Danziger, Colleen Heflin, Ariel Kalil, Judith Levine, Daniel Rosen, Kristin Seefeldt, Kristine Siefert, and Richard Tolman, "Barriers to the Employment of Welfare Recipients," Poverty Research and Training Center, University of Michigan, Revised Version, September 1999.

Edin, Kathryn and Laura Lein, Making Ends Meet: How Single Mothers Survive Welfare and Low-Wage Work (New York: Russell Sage Foundation, 1997).

Ellwood, David T., "The Impact of the Earned Income Tax Credit and Social Policy Reforms on Work, Marriage, and Living Arrangements," National Tax Journal, 53 (2000), 1063-1105.

Guydish, Joseph, Claudia Ponath, Alan Bostrom, Kevin Campell and Nancy Barron, "Effects of Losing SSI Benefits on Standard Drug and Alcohol Outcome Measures," Contemporary Drug Problems, 30 (2003), 169-193.

Henly, Julia R. and Sandra K. Danziger, "Confronting Welfare Stereotypes: Characteristics of General Assistance Recipients and Postassistance Employment," Social Work Research, 20 (1996), 217-227. 
Hopper, Kim, and Jim Baumohl, "Redefining the Cursed Word: A Historical Interpretation of American Homelessness." In Jim Baumohl, ed., Homelessness in America (Phoenix, AZ: Oryx Press, 1996), 3-14 (text); 221-224 (notes).

Hopper, Kim, Ezra Susser, and Sarah Conover, "Economies of Makeshift: Deindustrialization and Homelessness in New York City," Urban Anthropology, 14 (1985), 183-236.

Hunt, Sharon R. and Jim Baumohl, "Drink, Drugs and Disability: An Introduction to the Controversy," Contemporary Drug Problems, 30 (2003), 9-76.

Hunt, Sharon R. and Jim Baumohl, "Now Invited to Testify: Former Beneficiaries Appraise the SSI Drug Addiction and Alcoholism Program," Contemporary Drug Problems, 30 (2003), 455-499.

Johnson, Hans and Sonya Tafoya, "The Basic Skills of Welfare Recipients: Implications for Welfare Reform," Public Policy Institute of California, 1999.

The Lewin Group, Inc., and Westat, Inc., Policy Evaluation of the Effect of Legislation Prohibiting the Payment of Disability Benefits to Individuals Whose Disability Is Based on Drug Addiction or Alcoholism: Interim Report Submitted to the Social Security Administration (Fairfax, VA: Author), July 21, 1998.

Mashaw, Jerry L. and Virginia Reno, Balancing Security and Opportunity: The Challenge of Disability Income Policy (Washington, DC: National Academy of Social Insurance), 1996.

Merrill, Jeffrey C., Sarah Ring-Kurtz, Delia Olufokunbi, Sherril Aversa, and Jennifer Sherker, "Women on Welfare: A Study of the Florida WAGES Population." Unpublished manuscript, Treatment Research Institute, University of Pennsylvania School of Medicine, undated (ca. 1999).

National Public Radio, Morning Edition, "Supplemental Security Income," September 15, 1999. Audio stream available at: $<$ http://search.npr.org/ $\mathrm{cf} / \mathrm{cmn} / \mathrm{cmnpd} 0 \mathrm{Ifm} . \mathrm{cfm}$ ?PrgDate $=9 \% 2 \mathrm{~F} 15 \% 2 \mathrm{~F} 1999 \& \operatorname{PrglD}=3>$.

Norris, Jean, Richard Scott, Richard Speiglman, and Rex Green, "Homelessness, Hunger and Material Hardship Among Those Who Lost SSI," Contemporary Drug Problems, 30 (2003), 241-273.

Rangarajan, Anu, Peter Schochet, and Dexter Chu, "Employment Experiences of Welfare Recipients Who Find Jobs: Is Targeting Possible?" Mathematica Policy Research, Inc., Reference \#8428-600, August 1998. 
Schmidt, Laura, Constance Weisner, and James Wiley, "Substance Abuse and the Course of Welfare Dependency," American Journal of Public Health, 88 (1998), 1616-22.

Snow, David A., Leon Anderson, Theron Quist, and Daniel Cress, "Material Survival Strategies on the Street: Homeless People as Bricoleurs." In Jim Baumohl, ed., Homelessness in America (Phoenix, AZ: Oryx Press, 1996), 86-96 (text); 234-236 (notes).

SRA Technologies, Demonstration Project on Intensive Case Management for Drug Addicts and Alcoholics Receiving Supplemental Security Income (Alexandria, VA: Author), 1986.

Stone, Michael E., Shelter Poverty: New Ideas on Housing Affordability (Philadelphia: Temple University Press, 1993).

Swartz, James, Peggy Tonkin, and Jim Baumohl, "The Methodology of the Multi-Site Study of the Termination of Supplemental Security Income Benefits for Drug Addicts and Alcoholics," Contemporary Drug Problems, 30 (2003), 77-121.

Sweeney, Eileen P., "Recent Studies Indicate That Many Parents Who Are Current or Former Welfare Recipients Have Disabilities or Other Medical Conditions," Center on Budget and Policy Priorities, February $29,2000$.

United States Conference of Mayors, The Welfare Challenge Facing America's Cities: A 125-City Survey (Washington, DC: Author), November 1997.

United States Department of Health and Human Services, Administration for Children and Families, Office of Public Affairs, Welfare Caseloads, 1936-1999 (<http://www.acf.dhhs.gov/news/stats/ 3697.htm >).

White, William L., Slaying the Dragon: The History of Addiction Treatment and Recovery in America (Bloomington, IL: Chestnut Health Systems), 1998. 